\title{
HET GEBRUIK VAN MATHEMATISCHE STEEKPROEVEN IN DE ACCOUNTANTSCONTROLE
}

\author{
door A. van Heerden
}

\section{Inleiding}

Het gebruik van steekproeven in de accountantscontrole, waarvan omvang en uitvoering op mathematische grondslagen zijn bepaald, heeft sinds de tweede wereldoorlog in vele landen grote belangstelling gekregen. Onder meer nieuwe technieken op het terrein van de z.g. acceptance-sampling hebben daartoe bijgedragen.

In de uitgebreide litteratuur, die vooral in de Verenigde Staten op dit gebied is verschenen, wordt in het algemeen vrij sterk aansluiting gezocht bij kwaliteitscontrole zoals deze bij inkoop of produktie wordt gehanteerd. Daarbij wordt de massa zoals deze zich aan de accountant manifesteert, namelijk een massa posten van bepaalde aard in de administratie, als populatie genomen en ontstaan op grond van mathematisch bepaalde steekproeven gekwantificeerde uitspraken omtrent aantal of percentage foute posten in de onderzochte massa's. Er ontstaat dan een kwaliteitsoordeel omtrent die massa, zonder dat omtrent een belangrijk aspect van deze massa's, namelijk de in de administratie tot uitdrukking komende totaalbedragen, een directe kwantitatieve uitspraak kan worden gedaan.

In een beperkt aantal publikaties wordt aandacht besteed aan de totaalbedragen van de (mogelijke) foute posten, waarbij gewezen wordt op de mogelijkheden die daartoe geboden worden door gestratificeerde steekproeven. In het algemeen wordt daarbij de wijze waarop de stratificatie moet worden uitgevoerd niet vermeld. De eerste mij bekende mathematische uitwerking daarvan is van de hand van de Nederlandse Prof. P. de Wolff. $\left.{ }^{1}\right)^{2}$ )

Toch zal de controlerende accountant in veel gevallen behoefte hebben aan een techniek die hem tot een gekwantificeerde uitspraak omtrent het totaalbedrag van de mogelijke fouten in staat stelt. Een dergelijke techniek, die bepaalde voordelen biedt boven een stratificatie naar postgrootte wordt in deze bijdrage besproken. Voorts wordt een mogelijkheid aangegeven om te komen tot een objectieve vaststelling van de omvang van steekproeven, die worden toegepast op financiële gegevens. Beide voorstellen, zijn in 1961 in Nederland gepubliceerd ${ }^{3}$ ), uit welke publikatie bepaalde passages zijn overgenomen. Deze voorstellen hebben steun ontvangen van mathematisch-statistische zijde, doch de toepassingsmogelijkheden op het gebied van de accountantscontrole vormen nog een onderwerp van studie in Nederland.

\section{Guldenrangnummermethode}

\section{a. Eenheidskeuze}

De wijze waarop een te controleren postenreeks zich in feite manifesteert, wordt geheel losgelaten en in gedachten getransformeerd in een reeks guldens (de lezer zal mij vergeven, dat ik de Nederlandse munteenheid gebruik; uiteraard kan iedere

1) Wolff, P. de, Steekproeven bij administratieve controle. Statistica Neerlandica $1956 \mathrm{nr} .1$.

2) Wolff, P. de, Productiviteitsverhoging bij accountantscontrole door toepassing van gelaagde steekproeven. Statistica Neerlandica 1959 nr. 2.

3) Heerden, A. van, Steekproeven als middel van accountantscontrole. Maandblad voor accountancy en bedrijfshuishoudkunde $1961 \mathrm{nr} .11$. 
munteenheid daarvoor in de plaats gesteld worden, terwijl in daarvoor in aanmerking komende gevallen ook andere eenheden zoals kilogrammen, liters etc. toepasselijk kunnen zijn). Het betreft hier niet meer dan een keuze van de eenheden, waaruit de massa wordt geacht te bestaan ten behoeve van de selectic van de steekproef en de interpretatie van de uitkomsten. Het onderzoek van de voor onderzoek geselecteerde guldens zal in het algemeen worden uitgevoerd door onderzoek van de post, waarvan de gulden deel uitmaakt. Zoals hierna nog nader zal worden besproken, moet echter de gedachte worden vastgehouden dat de in het steekproefsgewijze onderzoek te betrekken eenheid slechts gevormd wordt door de specifieke aangewezen gulden.

\section{b. Selectie}

Wat betreft de selectie der te onderzoeken eenheden (guldens) in het algemeen geldt uiteraard de uit statistische handboeken bekende eis dat iedere in de steekproef te betrekken eenheid moet worden gekozen volgens een methode die aan iedere eenheid uit de gehele massa een gelijke kans biedt om te worden aangewezen. In de voorgestelde methodiek betekent dit, dat voor iedere gulden uit een te onderzoeken postenreeks een gelijke kans op trekking ontstaat. Dit wordt bereikt door aan iedere gulden een eigen rangnummer toe te kennen, zoals wordt gedemonstreerd door de volgende eenvoudige postenreeks:

\begin{tabular}{|c|c|c|c|}
\hline Post nr. & Bedrag & Cumulatief & $\begin{array}{l}\text { Guldenrang- } \\
\text { nummers }\end{array}$ \\
\hline 1 & $f \quad 10,-$ & $f \quad 10,-$ & $1 \mathrm{t} / \mathrm{m} \quad 10$ \\
\hline 2 & $\Rightarrow 25,-$ & $\Rightarrow 35,-$ & $11 \mathrm{t} / \mathrm{m} \quad 35$ \\
\hline 3 & $, 100,-$ & $, 135,-$ & $26 \mathrm{t} / \mathrm{m} 135$ \\
\hline 4 & $" 50,-$ & $, 185,-$ & $136 \mathrm{t} / \mathrm{m} 185$ \\
\hline \multirow[t]{2}{*}{5} & $" 75,-$ & $, 260,-$ & $186 \mathrm{t} / \mathrm{m} 260$ \\
\hline & $f 260,-$ & & \\
\hline
\end{tabular}

Aan de hand van dit voorbeeld zal het duidelijk zijn dat ieder guldenrangnummer niets anders is dan het cumulatieve totaal tot en met de daardoor aangeduide gulden en het hoogste guldenrangnummer wordt gevormd door het eindtotaal van de gehele postenreeks. Het is voorts gemakkelijk in te zien dat iedere post in de totale nummerserie voorkomt met een aantal guldenrangnummers dat gelijk is aan het bedrag van die post in guldens.

De aanwijzing van de te onderzoeken guldens geschiedt daarbij aan de hand van willekeurige nummers uit een serie die loopt van 1 tot en met het getal dat het totaalbedrag van de betrokken postenreeks in guldens aangeeft.

\section{c. Eenvoudige steekproef}

Aangezien slechts beoogt wordt de voordelen van de aangegeven eenheidskeuze te belichten, wordt alleen een enkelvoudige steekproef beschreven. Meer verfijnde steekproeftechnieken, zoals bijv. sequential sampling, zijn bij deze eenheidskeuze uiteraard op overeenkomstige wijze toepasselijk.

Stellen wij als eis, dat een postenreeks op zodanige wijze gecontroleerd moet 
worden dat behoudens een risico $\varepsilon$ van het totaalbedrag niet meer dan een fractie $\varphi$ foutief is. Indien het gezamenlijk bedrag van de foute posten juist een fractie $\varphi$ van het totaalbedrag zou uitmaken, dan zouden deze foute posten gezamenlijk vertegenwoordigd worden door een aantal guldenrangnummers dat eveneens een fractie $\varphi$ van de gehele rangnummerserie uitmaakt. Wordt nu een willekeurig rangnummer uit de serie getrokken dan is de kans:

- een foute post te treffen: $\varphi$

- een goede post te treffen: $(1-\varphi)$

De kans in een serie van $\mathrm{n}$ trekkingen uitsluitend goede posten aan te treffen (m.a.w. van het verschijnsel ,fout" niets te merken) is:

$$
(1-\varphi)^{\mathbf{n}}
$$

Wil men bij een fout-fractie $\varphi$ dus slechts een kans $\varepsilon$ lopen geen fout te vinden, of wat hetzelfde is slechts een kans $\varepsilon$ te lopen de verkeerde beslissing te nemen dat de postenserie goed is, dan zullen wij n zo moeten kiezen dat

$$
(1-\varphi)^{\mathbf{D}}=\varepsilon
$$

of:

$$
\mathrm{n}=\frac{\ln \varepsilon}{\ln (1-\varphi)}
$$

Een steekproef van deze omvang, waarin geen fouten worden aangetroffen levert dan de gevraagde kwantitatieve uitspraak omtrent het totaalbedrag.

\section{d. Nadere eigenschappen van de methode}

De methode heeft de volgende speciale eigenschappen:

1 De methode wijst als object van controle aan niet een post doch een bepaalde gulden van die post. Dat wil zeggen: indien het nummer de 50ste gulden treft van een post groot $f 100$, - en het stuk dat deze post moet dekken geeft slechts $f 80$, - aan, dan is de aangewezen gulden gedekt en de uitspraak omtrent het totaalbedrag wordt niet aangetast.

$2 \mathrm{Bij}$ de aanwijzing van de te controleren post op grond van een bepaald rangnummer kan direct van het hoogste daaraan voorafgaande subtotaal worden uitgegaan met cumulatief tellen. Op grond van het tellen, verricht ter selectic van de posten heeft men dan, zonder enig verder telwerk, de totaaltelling gecontroleerd met dezelfde betrouwbaarheid als voor het constateren van fouten tot uitgangspunt is gekozen.

Het best is dit te demonstreren aan de hand van een eenvoudig voorbeeld. 


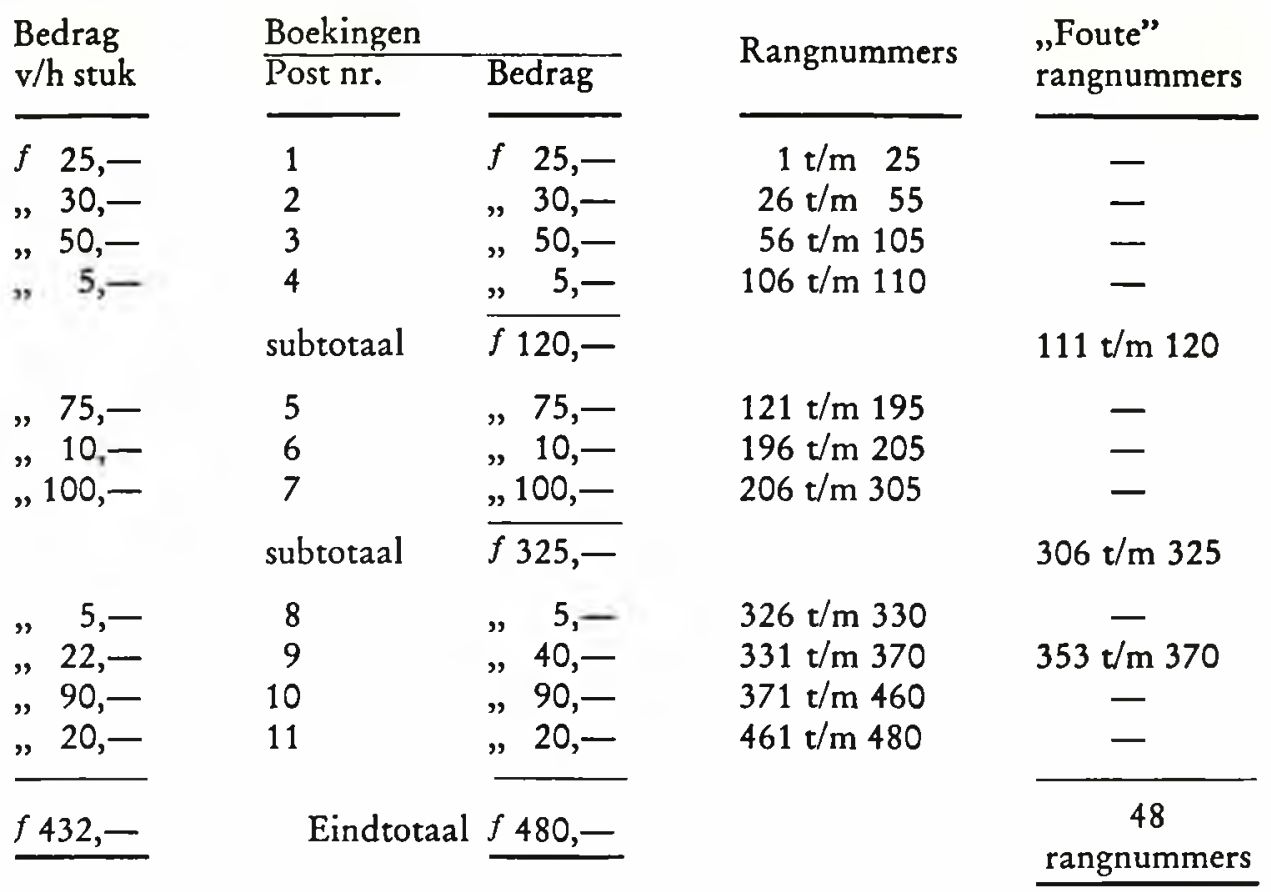

In dit voorbeeld is een totaalfout van $10 \%$ of $f 48$, - gemaakt, gedeeltelijk door telfouten $(f 30,-)$ gedeeltelijk door te hoge boekingen $(f 18,-)$. Bij bestudering van dit voorbeeld blijkt dat de „,fout", of dit nu een te hoge boeking of een telfout is, vertegenwoordigd moet zijn met een aantal rangnummers, dat gelijk is aan het totaalbedrag van die fout en dus onderworpen aan de eerder gegeven waarschijnlijkheidsberekening. Men lette daarbij op het feit dat als foute rangnummers alleen zijn beschouwd de laatste 18 van post 9 (eigenschap 1.) en dat de guldens van de posten na elk subtotaal zijn genummerd van dat subtotaal uitgaand. (eigenschap 2.)

\section{e. Statistisch voordeel van de methode}

Indien administratieve massa's met behulp van steekproeven worden gecontroleerd, rijst steeds de moeilijkheid of een geselecteerde eenheid als fout of als goed moet worden beschouwd. Nemen wij als voorbeeld de controle op debiteuren door middel van een gestratificeerde steekproef. In de steekproef komt een grote vordering (bijv. $f$ 100.000) op een bepaalde debiteur voor, waarvan bij onderzoek blijkt dat een creditnota van een relatief klein bedrag (bijv. $f 1.000$ ) ten onrechte niet in mindering is gebracht. Uit een oogpunt van de kwaliteit van de administratie is hier uiteraard sprake van een fout. Doch indien wordt uitgegaan van de vraag of het totaalbedrag van de fouten een bepaalde grens overschrijdt, is bij toepassing van een gestratificeerde steekproef het antwoord niet te geven.

Indien de te onderzoeken eenheid wordt geïdentificeerd als een bepaalde gulden volgt de uitspraak of de getroffen eenheid fout of goed is, automatisch uit de plaats van die gulden in het onderzoek saldo. In het gegeven voorbeeld zijn de eerste 99.000 guldens ,goed” en de laatste 1.000 guldens „,fout”. Door dit scherpe 
onderscheid kan de conclusie uit de steekproef mathematisch exact worden aangegeven en kan, indien sequential sampling wordt toegepast, exact worden aangegeven of de steekproef moet worden voortgezet.

\section{Mogelijkheid tot objectieve bepaling van de omvang van te verrichten steek- proeven}

\section{a. Eerste benadering}

Indien in een bepaalde situatie tot controle door middel van steekproeven wordt besloten, dan rijst de vraag welke grenzen moeten worden gesteld voor de twee elementen (tolerantie en toegelaten risico) die onverbrekelijk aan het waarnemen door middel van steekproeven verbonden zijn. De mathematische steekproef door zijn exacte berekening van tolerantie en risico geeft weliswaar reeds een meer objectieve grondslag aan de bepaling van de controle-omvang, doch indien de waarden voor deze twee elementen subjectief worden bepaald, zou er in zekere zin sprake zijn van een verplaatsen van de moeilijkheid.

Voor de analyse van dit probleem is uitgegaan van twee veronderstellingen ten aanzien van het nut van de ontdekking van fouten enerzijds en de verwerking van het risico-element anderzijds:

1 Het ,nut" van het vinden van een fout bij de controle is gelijk aan het bedrag van die fout.

2 Het risico van niet-ontdekking mag worden ingecalculeerd door vermenigvuldiging van dat risico met het bedrag waarover het risico wordt gelopen.

Voor een enkelvoudige steekproef kan dan de volgende redenering worden gevolgd.

Op grond van de twee bovengenoemde premissen kan men de „waarde" van het risico, dat gelopen wordt door een deel der detailcontrole achterwege te laten (restrisico), indien men zich op een steekproefsgewijze controle baseert, als volgt uitdrukken: ,(mogelijke) fout $\times$ risico van niet-ontdekking”.

De berekening van deze "waarde" geschiedt door vermeniguuldiging van de eerder genoemde waarden voor $\varphi$ en $\varepsilon$. De grootte van de fout is a priori niet bekend. Het bovenaangegeven produkt heeft echter, gegeven een bepaalde steekproefomvang, een maximum waarde. Zoals in de appendix nader is aangetoond, wordt dit maximum bij een steekproefomvang $(\mathrm{n})$ bereikt, indien de fout $=$

$\frac{\mathrm{T}}{\mathrm{n}}$ (waarin $\mathrm{T}=$ totaalbedrag van de postenreeks) bij welke fout het risico van niet-ontdekking gelijk wordt aan $\frac{1}{\mathrm{e}}=0,368$. De maximumwaarde van de eerder gegeven vorm: „(mogelijke) fout $\times$ risico van niet-ontdekking” kan dus bij een steekproefomvang van $n$ geschreven worden als

$$
\frac{1}{\mathrm{e}} \times \frac{\mathrm{T}}{\mathrm{n}}=0,368 \frac{\mathrm{T}}{\mathrm{n}}
$$

We hebben thans een uitdrukking voor de maximumwaarde van het risico van niet-ontdekking voor een willekeurige steekproefomvang. De vraag die nu gesteld moet worden is: Bij welke steekproefomvang zullen de kosten verbonden aan het verder uitbreiden van de controle gelijk zijn aan resp. groter worden dan de ver- 
mindering van de waarde van het „restrisico”. Voor de bepaling van deze grens zij verwezen naar de appendix. Het blijkt, dat deze grens bereikt wordt bij de steekproefomvang

$$
\begin{aligned}
\mathrm{n} & =\sqrt{\frac{\mathrm{T}}{2,718 \times \mathrm{k}}} \\
\text { waarin: } \mathrm{T} & =\text { totaalbedrag der te onderzoeken massa } \\
\mathrm{k} & =\text { controlekosten per te onderzoeken eenheid }
\end{aligned}
$$

\section{b. Introductie van het vertrouwen dat kan worden gesteld in de interne organisatie}

In het voorgaande is nog geen rekening gehouden met het feit dat de interne organisatie in een gunstige situatie zo zal zijn dat fouten van enige betekenis niet of bijna niet zullen voorkomen. Stellen wij deze kans voor door een factor c, dan kan een exacte waarde daarvan uiteraard niet gegeven worden wel kan gezegd worden dat de factor $\mathrm{c}$ kleiner is naarmate de interne organisatie beter is verzorgd.

Introduceren wij de factor $c$ in de hiervoor gegeven benadering, dan kan men de waarde van het restrisico voorstellen als het product:

$$
\mathrm{c} \times \frac{\mathrm{T}}{\mathrm{n}} \times \frac{1}{\mathrm{e}}
$$

De formule voor de steekproefomvang wordt dan

$$
\mathrm{n}=\sqrt{\frac{\mathrm{c} \times \mathrm{T}}{2,718 \times \mathrm{k}}} \text { (zie appendix) }
$$

Hoewel een waarde voor $\mathrm{c}$ slechts gevoelsmatig kan worden benaderd, blijkt uit de formule wel dat de steekproefomvang kleiner behoort te zijn naarmate de interne organisatie beter is.

\section{Praktische toepassing}

\section{a. Steekproefmethode}

Voor de accountant zal als regel acceptance-sampling in aanmerking komen. Bij vele praktische toepassingen is mij gebleken, dat vrijwel steeds met een enkelvoudige steekproef kan worden volstaan, in gevallen waarin het bedrag van de (mogelijke) totaalfout als criterium wordt gehanteerd.

Voorwaarde hiertoe is uiteraard dat de door de accountant gehanteerde maximum foutgrens aanzienlijk hoger ligt dan de foutfractie die in feite in de administratie aanwezig blijkt te zijn. Gezien de doelstelling van de accountantscontrole zal dit ook vrijwel steeds het geval zijn. Daarnaast is echter van belang de foutdefinitie zoals deze eerder is gegeven en die bij kleine afwijkingen in bepaalde posten niet tot afkeuring van de getroffen eenheid behoeft te leiden.

\section{b. Selectie}

De aanwijzing van guldens in plaats van posten heeft in meerdere gevallen tot een vrij bewerkelijke selectie geleid. Hierin is soms veel besparing bereikt door medewerking van de administratie, die ingeval mechanische of elektronische apparatuur werd gebruikt, zonder noemenswaardige extra kosten frequente tussentel- 
lingen afdrukte. In een enkel geval werd zelfs na iedere post een cumulatief totaal afgedrukt, die directe anwijzing van de te onderzoeken eenheden mogelijk maakte.

Indien elektronische apparatuur in gebruik is, kan de selectie uiteraard met behulp van deze apparatuur worden verricht. Met name is daarvan gebruik gemaakt in een geval van voorraadopneming, waarbij de administratie van de voorraden alleen in $\mathrm{kwantiteiten}$ werd gevoerd. De waardeomrekening, cumulatieve telling en selectie van de te inventariseren posten werden daarbij in één arbeidsgang verricht. Dit laatste bleek in een ander geval zelfs mogelijk bij gebruik van gewone ponskaartenapparatuur. In dat geval moesten vaste intervallen tussen de te selecteren guldens worden aangehouden.

\section{c. Berekende steekproefomvang}

Hantering van de voorgestelde formules ter bepaling van een objectieve steekproefomvang moet voorlopig rog als een experiment worden beschouwd. Wel is in het algemeen gebleken dat de uitkomsten in een orde van grootte lagen die ook uit een subjectieve benadering aanvaardbaar was.

\section{Toepassing in de interne controle}

In het voorgaande is de guldenrangnummermethode behandeld als steekproefmethode voor de controle van postenreeksen in het kader van de accountantscontrole. Ook bij de interne controle kan toepassing nuttig zijn. Nemen wij als voorbeeld de controle op de te betalen facturen. Deze kan in grote bedrijven tot een groot en kostbaar controle-apparaat leiden, waarbij soms blijkt dat de gevonden fouten niet opwegen tegen de kosten van de controle. Toch wordt deze controle vaak volledig gehandhaafd uit vrees dat afschaffing tot ongecontroleerde verliezen zou kunnen leiden. Indien de ervaring met binnenkomende facturen gunstig is, zou een op de beschreven wijze uitgevoerde steekproefcontrole tot besparing kunnen leiden. Men blijft de mogelijke verliezen kwantitatief beheersen en kan dus steeds de besparing op de controlekosten daartegen afwegen.

\section{APPENDIX}

\section{Maximumwaarde fout $\times$ risico}

Stel: steekproefomvang $=\mathbf{n}$ totaalbedrag der te onderzoeken massa $=\mathrm{T}$

fractie foute guldens $=\varphi$

Het risico, dat in de steekproef van n guldens niet éen der foute guldens voorkomt is

$$
(1-\varphi)^{\mathbf{n}}
$$

en het produkt $A$ van fout $X$ risico kan dus worden geschreven als:

$$
\mathrm{A}=\varphi \mathrm{T}(1-\varphi)^{\mathrm{n}}
$$


Voor gegeven $n$ wordt een extreme waarde bereikt wanneer:

$$
\begin{aligned}
\frac{\mathrm{da}}{\mathrm{d} \varphi} & =(1-\varphi)^{\mathrm{n}} \mathrm{T}-\mathrm{n} \varphi \mathrm{T}(1-\varphi)^{\mathrm{n}-1} \\
& =(1-\varphi)^{\mathrm{n}-1} \mathrm{~T}(1-\varphi-\mathrm{n} \varphi)=0
\end{aligned}
$$

of

$$
\varphi=\frac{1}{\mathrm{n}+1}
$$

Gemakkelijk valt in te zien, dat de tweede afgeleide

$$
\frac{\mathrm{d}^{2} \mathrm{~A}}{\mathrm{~d} \varphi^{2}} \text { voor } \varphi=\frac{1}{\mathrm{n}+1}
$$

negatief is, zodat de waarde van A maximaal is voor

$$
\varphi=\frac{1}{\mathrm{n}+1} \sim \frac{1}{\mathrm{n}}
$$

Substitutic in (1) geeft met $\left(1-\frac{1}{\mathrm{n}}\right)^{\mathrm{n}} \sim \frac{1}{\mathrm{e}}$

$$
\mathrm{A}_{\max }=\frac{\mathrm{T}}{\mathrm{en}}
$$

\section{Economische grens der controle-omvang}

De annotatie onder I wordt aangehouden, terwijl de controlekosten per te onderzoeken post worden voorgesteld door $\mathrm{k}$.

De vraag is nu bij welke waarde van n de kosten van voortzetting der controle hoger zijn dan de daardoor bereikte vermindering van de waarde van het „restrisico":

$$
A_{\max }=\frac{T}{\text { en }}
$$

De totale controlekosten kunnen worden voorgesteld door nk en de vraag wordt dan, bij welke waarde van $\mathrm{n}$ de vorm ${ }_{\text {en }}^{\mathrm{T}}$ minder daalt dan nk stijgt indien wij $\mathrm{n}$ laten toenemen.

Differentiatie van beide vormen naar $n$ en gelijkstelling levert op

$$
\frac{\mathrm{T}}{\mathrm{en}^{2}}=\mathrm{k}
$$

zodat de gevraagde waarde van $n$ wordt gevonden als

$$
\begin{aligned}
\mathrm{n} & =\sqrt{\frac{\mathrm{T}}{\mathrm{ek}}} \\
& =\sqrt{\frac{\mathrm{T}}{2,718 \mathrm{k}}}
\end{aligned}
$$


III Economische grens der controle-omvang, indien rekening wordt gehouden met de kans dat fouten voorkomen

Zij de kans dat fouten voorkomen c. Deze kans wordt bepaald door de sterkte der interne organisatie en controle, is echter onafhankelijk van de omvang der externe controle (n).

Overeenkomstig het gestelde in pagina 12 onder $\mathrm{b}$. is de waarde van het restrisico in dat geval

$$
\frac{\mathrm{cT}}{\mathrm{en}}
$$

Dit gesteld tegenover de controlekosten $\mathrm{n} \times \mathrm{k}$ geeft nu als economische grens der controle-omvang:

$$
\mathrm{n}=\sqrt{\frac{\mathrm{cT}}{2.718 \mathrm{k}}}
$$

